\title{
Absence of association of IFNL3/IL28B rs 12979860 and IFNL4 ss 469415590 polymorphisms with the neurological status of HTLV-1 Afro-Caribbean subjects in Martinique.
}

Severine Jeannin ${ }^{1 *}$, Jean-Marc Costa ${ }^{4}$, Jean-Dominique Poveda ${ }^{4}$, Gilda Belrose ${ }^{2}$, Agnes Lezin $^{2}$, Andre Cabie $^{3}$, Raymond Cesaire' ${ }^{2}$ Stephane Olindo ${ }^{1}$

From 17th International Conference on Human Retroviruses: HTLV and Related Viruses

Trois llets, Martinique. 18-21 June 2015

\section{Background}

The polymorphism of Interferon-lambda3/Interleukine28B (IFNL3/IL28B) rs 12979860 has been described as important in the development of HTLV-1-associated myelopathy/spastic paraparesis (HAM/TSP). Recently, the dinucleotide polymorphism, IFNL4 ss469415590 has been discovered and is in high linkage disequilibrium with rs12979860. In a transversal study, we aimed to examine the polymorphisms of these two nucleotides in our HTLV-1 Afro-Caribbean population.

\section{Methods}

The frequencies of the CC, CT and TT genotypes of the single nucleotide rs12979860 and the frequencies of $\Delta \mathrm{G} / \Delta \mathrm{G}, \Delta \mathrm{G} / \mathrm{TT}$ and TT/TT genotypes of the dinucleotide ss 469415590 are reported in the entire HTLV-1 group and compared between asymptomatic individuals and HAM/TSP patients.

\section{Results}

In our $94 \mathrm{HTLV}-1$ subjects, frequencies of rs1299860 were CC, $13.3 \%$; CT, $44.7 \%$; TT, $42 \%$ and frequencies of ss469415590 genotypes were $\Delta \mathrm{G} / \Delta \mathrm{G}, 45.7 \% ; \Delta \mathrm{G} / \mathrm{TT}$, $42.6 \%$; TT/TT, $11.7 \%$. We found no significant difference in allele distribution in both studied nucleotide polymorphism between 53 asymptomatic carriers (60.7 years and $72 \%$ females) and 41 HAM/TSP patients (70 years and $80 \%$ females).

'Service de Neurologie, Centre Hospitalier Universitaire de Martinique, Fortde-France Cedex, Martinique

Full list of author information is available at the end of the article

\section{Conclusion}

In our population, the polymorphisms of IFNL3/IL28B rs12979860 and IFNL4 ss469415590 are not associated with HTLV-1 neurological phenotype status. Different genotypes target should be considered.

\section{Authors' details}

'Service de Neurologie, Centre Hospitalier Universitaire de Martinique, Fortde-France Cedex, Martinique. ${ }^{2}$ Service de Viro-Immunologie, Centre Hospitalier Universitaire de Martinique, Fort-de-France Cedex, Martinique. ${ }^{3}$ Service des maladies Infectieuses, Centre Hospitalier Universitaire de Martinique, Fort-de-France Cedex, Martinique. ${ }^{4}$ Pasteur-CERBA, CergyPontoise, France.

Published: 28 August 2015

doi:10.1186/1742-4690-12-S1-P95

Cite this article as: Jeannin et al:: Absence of association of IFNL3/IL28B rs 12979860 and IFNL4 ss 469415590 polymorphisms with the neurological status of HTLV-1 Afro-Caribbean subjects in Martinique. Retrovirology 2015 12(Suppl 1):P95.

Submit your next manuscript to BioMed Central and take full advantage of:

- Convenient online submission

- Thorough peer review

- No space constraints or color figure charges

- Immediate publication on acceptance

- Inclusion in PubMed, CAS, Scopus and Google Scholar

- Research which is freely available for redistribution 